\title{
Joaquim Nabuco, espectador do século (e de si mesmo)
}

Melânia Silva de Aguiar Pontifícia Universidade Catóica de Minas Gerais

Resumo: A extensa obra produzida por Joaquim Nabuco (1849-1910) ao longo da vida, graças a sua atuação política e participação expressiva no movimento abolicionista, oferece testemunho importante para a compreensão dos principais acontecimentos de fins do século XIX e princípios do XX no Brasil, época de transformaçôes profundas no cenário nacional. Sua obra de cunho memorialístico, representada, sobretudo, pelo livro Minha Formação, apesar de ter sua importância reconhecida pelos leitores em geral, é com frequencia alvo de críticas nem sempre justas, se considerarmos o contexto histórico e literário do tempo. Pretende-se aqui relativizar algumas dessas críticas, vendo no memorialista o grande escritor, reformador social, observador dos acontecimentos e, em paralelo, espectador de si mesmo.

Palavras-chave: Joaquim Nabuco; memorialismo; recepção.

No Prefácio com que veio a introduzir sua famosa autobiografia Minha Formação, Joaquim Nabuco se pergunta, tendo diante de si as páginas reunidas em forma de livro, qual será a impressão delas junto ao público:

Está aí muito da minha vida... Será uma impressão de volubilidade, de flutuação, de diletantismo, seguida de desalento, que elas comunicarão? Ou antes de consagração, por um voto perpétuo, a uma tarefa capaz de 
saciar a sede de trabalho, de esforço e de dedicação da mocidade (...) renúncia à política, depois de dez anos de retraimento forçado (...). ${ }^{1}$

E embora receie que a impressão possa ser "misturada", parece confiante no julgamento da posteridade, pois acredita que não precisará pleitear em causa própria, uma vez que sua obra

será julgada pela raça mais generosa que todas... (...) Infeliz de quem entre nós não tem outro talento ou outro gosto senão o de abater! A nossa natureza está voltada à indulgência, à doçura, ao entusiasmo, à simpatia, e cada um pode contar com a benevolência ilimitada de todos...

Cônscio, portanto, do caráter "flutuante", oscilante de seu escrito, o que - sabe-se - é inevitável em obras de cunho memorialístico, sobretudo se elas pretendem cobrir um largo espaço de tempo vivido, Nabuco mostra-se preocupado com o efeito ou a "impressão" que seu livro causará, apesar de, aparentemente, confiar no julgamento "generoso" de seus leitores. Escrito entre 1893 e 1899, e publicado integralmente em 1900 (a maior parte já havia aparecido no Comércio de São Paulo, em 1895), Minha Formação abrange desde a infância do autor até os anos de reclusão política (entre 1889 e 1899), não necessariamente em ordem cronológica. Passando pelo período efervescente dos embates políticos, pela visita transformadora à Europa ("a passagem da crisálida para a borboleta") e aos Estados Unidos, pela empenhada luta abolicionista, pelo advento da república, convicto monarquista que foi, é na reclusão dos últimos tempos que encontra o ambiente propício à rememoração e registro desses anos:

De 1889 a 1890 estou sob a impressão do 15 de Novembro seguindo-se ao 13 de Maio; escrevo então os meus solilóquios em uma Tebaida onde podia andar centenas de milhas sem deparar com o refúgio de outro praticante... Em 1891 minha maior impressão é a morte do Imperador. ${ }^{3}$

A religião, "a volta misteriosa, indefinível da fé, para mim verdadeira pomba do dilúvio universal, trazendo o ramo da vida renascente...”, como diz,

1. NABUCO. Minha formação, p. 27-28.

2. NABUCO. Minha formação, p. 28.

3. NABUCO. Minha formação, p. 239. 
marcará o intervalo de 1892-1893, seguido do assunto que seria sua "grande devoção literária", a vida de seu pai, que o absorverá durante seis anos.

A "volubilidade", a "flutuação", o "diletantismo", o "desalento", vistos pelo autor como possíveis falhas de seu livro, não ocuparão de fato o espírito dos críticos. Gilberto Freire, em sua Introdução a Minha Formação, ressalta na obra outras "deficiências", como, por exemplo, as muitas lacunas do ponto de vista autobiográfico, observando que "O que consta de Minha Formação é apenas parte de uma grande vida. O que aí se revela é apenas parte de uma complexa personalidade". E ainda, mais à frente:

A formação de Joaquim Nabuco não parou aos cinquenta anos: idade em que deu forma definitiva à Minha Formação. Este livro, Nabuco parece o ter escrito, pensando com Montaigne, que já se dera bastante aos outros; e que tinha o direito e, talvez, o dever de, à base das experiências por ele já vividas, dar-se principalmente a si mesmo, contemplando-se, analisando-se, aperfeiçoando-se no seu modo interior de ser, escrevendo a história de sua própria vida ou da sua própria pessoa sem temer a acusação de narcisismo da parte de críticos mais ou menos levianos.

No entanto, o temor de ser taxado de narcisista mereceria de fato a preocupação do memorialista Nabuco. Com todos os elogios que o autor recebeu dos contemporâneos e dos leitores póstumos, é frequente a alusão ao narcisismo presente em Minha Formação, como se a escrita de si, por mais discreta que seja a referência aos feitos e aos fatos vividos, não encerrasse sempre essa dose de auto-satisfação ou, pelo menos, de justificativa para ações menos nobres. Gilberto Freire parece ser dos poucos cujo proclamado "narcisismo" de Nabuco não incomoda tanto. Chega mesmo a reclamar do autor pernambucano uma história mais pessoal, voltada menos para os fatos externos, e mais para sua vida íntima, para o trivial, o cotidiano, "o sal daquele anglicíssimo sense of humour que leva o indivíduo, mesmo como homem público, a sorrir de si próprio; a admitir na sua vida ou na sua pessoa, fraquezas que o tornem ridículo e até cômico aos olhos dos outros." (o que não deixa de ser um modo, ainda, de colocar-se no centro das atenções).

4. FREIRE, in NABUCO. Minha formação, p. 13.

5. FREIRE, in NABUCO. Minha formação, p. 17. 
De fato, o cotidiano, o trivial, o relato íntimo não são mesmo a nota dominante em Minha Formação, e o capítulo frequentemente citado como ponto alto do livro ("Maçangana"), onde o autor fala de sua infância no engenho de Maçangana, vivendo sob o carinho e proteção de sua rica e prestigiada madrinha, Dona Ana Rosa Falcão, é enxertado no livro com uma observação que anuncia o capítulo e que é quase um pedido de desculpas do autor: "Como eu disse, porém, há pouco, eu trazia da infância o interesse pelo escravo... Esse episódio não será talvez descabido nestas recordações." E mais adiante, em pé de página:

A razão que me fez não começar pelos anos da infância foi que estas páginas tiveram, ao ser primeiro publicadas, feição política que foram gradualmente perdendo, porque ao escrevê-las diminuía em mim o interesse, a sedução política. (...) É deste livro, de caráter muito íntimo, composto em francês há sete anos, que traduzo este capítulo para explicar a referência feita às minhas primeiras relações com os escravos.

Percebe-se, assim, nas palavras de Nabuco, o cuidado em não exagerar o lado pessoal, o que, exatamente, lhe é cobrado por Gilberto Freire. A bem da verdade, a Introdução de Gilberto Freire à Minha formação oscila entre o elogio enfático - "uma das expressões mais altas da literatura em língua portuguesa", e a observação um tanto contraditória de que a autobiografia, Nabuco "escreveu-a, contemplando-se, por vezes, com não pouca satisfação" e, embora introspectivo, "guardando-se de revelar o que pudesse fazê-lo parecer ridículo aos olhos dos leitores"; esta, a grande deficiência, na visão de Freire, de Minha formação.

Como se sabe, a escrita da memória, real ou fingida, em seus vários formatos (diários, autobiografias, cartas), tornou-se na Europa, a partir do século XVIII, com a ascensão da burguesia e o culto da individualidade, um expediente comum, havendo desde então uma proliferação de histórias de vida, emolduradas ou cunhadas de formas distintas, segundo o móvel, ou os móveis que costumam levar o indivíduo a essa escrita de si. A valorização do "eu”, impensável no século

6. NABUCO. Minha formação, p. 178.

7. NABUCO. Minha formação, p. 179. 
XVII, pois o indivíduo não existe sob o poder absolutista (lembre-se, a propósito, de Pascal, a frase famosa "Le moi est haïssable") ganha força no século das Luzes, quando a noção de indivíduo se faz mais e mais precisa numa sociedade liberal aberta às novidades.

No Brasil, o espírito conservador, infenso às mudanças em qualquer terreno da vida em sociedade, não veria com bons olhos esse tipo de escrita, mesmo já entrando o século XX no momento em que sai Minha Formação. É ainda Gilberto Freire quem lembra, um tanto ironicamente, a recepção desse "livro escandaloso, por ter sido, para muitos, cheio de louvor em boca própria", obra de um "deselegante narciso".

Sucede que, nesse tipo de escrita, é relativamente comum a pose para a posteridade, o desejo de fazer uma bonita figura para as gerações por vir, e é quando as memórias, mais do que "documentos", constroem um tipo de realidade, não propriamente adulterada, mas apresentada, na maioria das vezes, sob uma ótica condescendente em relação ao que escreve, em que tudo se justifica ou se explica. Como bem observa Luiz Costa Lima:

(...) memórias e autobiografias são substitutos dos espelhos. Se estes, metálicos e implacáveis, assinalam o desgaste dos traços, o torpor dos olhos, a redondez do ventre, fechamo-nos contra a maldade dos espelhos e procuramos nos rever no que fomos, como se o percurso da antiga paisagem nos capacitasse a nos explicar ante nós mesmos. ${ }^{8}$

Mas há ainda um modo mais velado de manifestação desse malvisto narcisismo, tão criticado nas obras de memórias (e, acentuadamente, na de Joaquim Nabuco); ou ainda, dizendo de outra forma: ocorre, não poucas vezes, a manifestação mais sutil desse narcisismo, por meio de um "embelezamento" da linguagem, de uso mais propriamente literário, que atrai pelos recursos retóricos, pela filigrana estilística, pelos vôos da imaginação, pelo apelo direto aos sentimentos, de tal modo que nós, leitores, somos levados a esquecer o homem que está por detrás da escrita, e a nos concentrar nesse magnífico escritor, semi-deus fascinado por sua criação refletida no espelho da página, com tal capacidade de sugerir e despertar imaginário e emoções adormecidas. Nesse caso, já não somos inclinados a separar o autor de carne e osso do autor textual, mas levados a fundi-los num só,

8. LIMA. Sociedade e discurso ficcional, p. 244. 
conquistando-nos, os dois, definitivamente. De um modo ou de outro, se bem avaliados, o contar-se esmerilhadamente mistura-se ao posar, de forma mais aberta ou mais velada, pois o autoelogio, pose para o futuro, não é muito diferente do posar através da linguagem trabalhada, visando ao elogio, ao reconhecimento.

Em ensaio muito conhecido, "Poesia e ficção na autobiografia", Antonio Candido evidencia, com bastante clareza, sua simpatia ou atração pelas autobiografias que ele classifica de poéticas ou ficcionais, produzidas por autores mineiros, e que se apresentam como se fossem produtos da imaginação, mesmo "quando não acrescentam elementos imaginários à realidade". Os recursos aí utilizados, "próprios da ficção e da poesia", a seu ver, acabam acrescentando a essas obras "um acentuado cunho de universalidade", o que, a rigor, segundo observa, não era de se esperar de algo tão pessoal como sejam as autobiografias. Esse traço das autobiografias feitas por mineiros se explicaria de algum modo pelo "fato de a produção literária ter surgido em Minas, no século XVIII, com um acentuado cunho de universalidade"; por outro lado, o gosto dos mineiros pela literatura na primeira pessoa, "em particular a autobiografia", representaria, à primeira vista, por seu caráter particularizador - pondera o crítico - uma tendência oposta.

Em Minha formação, Antonio Candido vai encontrar elementos que a distanciam, justamente, desses traços, digamos assim, "positivos" dos mineiros, ressaltados nas obras em que poesia e ficção marcam sua presença. Dentre essas, focaliza Minhas recordações, do mineiro Francisco de Paula Ferreira de Resende (1832-1893), "escritor direto e aparentemente tosco", mas de estilo "peculiar e original". Veja-se:

No famoso Minha Formação, Joaquim Nabuco atenua o caráter exemplar do que narra, porque traz a primeiro plano uma personalidade bastante narcísica, embora eminente, dando exemplo de como o dado pessoal pode se dissolver na vaidade, a mais particularizadora das forças que atuam em nós. Ferreira de Resende, ao contrário, alcança naturalmente o cunho generalizador através da sua candura arguta e do desejo de fazer viver o seu tempo e o seu meio, graças ao relato da sua vida. ${ }^{10}$

9. CANDIDO. A educação pela noite e outros ensaios, p. 51-69.

10. CANDIDO. A educação pela noite \& outros ensaios, p. 53. 
E mais adiante:

Por tudo isso, depois de Marília de Dirceu, tomemos Minhas recordações como exemplo da capacidade demonstrada por tantos mineiros de, inserindo o eu no mundo, mostrar os aspectos mais universais nas manifestações mais particulares, num avesso da autobiografia estritamente individualista do tipo Nabuco, da qual o interesse é de outro tipo e consiste em reduzir o geral à contingência do particular. ${ }^{11}$

Nessas passagens, extraídas de um ensaio, como sempre brilhante, como o são os saídos da pena de Antônio Candido, ficam claras as restrições do crítico a Nabuco, nas alusões ao caráter pouco exemplar de sua obra, à sua personalidade narcísica, à dissolução do dado pessoal na vaidade, e ainda, na referência à redução do geral "à contingência do particular". Por outro lado, a menção, como que pelo avesso, aos aspectos contrários, isto é, ao cunho generalizador das memórias de Ferreira de Resende, a sua candura arguta e ao desejo de fazer viver o seu tempo e o seu meio é uma clara manifestação do valor concedido a este em detrimento do primeiro.

São ainda valorizadas, entre outras, além da obra dos árcades, os livros da diamantinense Helena Morley (Minha vida de menina), pela graça e espontaneidade da escrita, de Carlos Drummond de Andrade (Boitempo e Menino antigo), de Murilo Mendes (A idade do serrote), de Pedro Nava (Baú de ossos). Nas obras dos três últimos, Candido se detém em análise minuciosa, ressaltando aquela positiva universalidade acima mencionada, obtida em grande parte pelo recurso a uma linguagem que extrapola o meramente factual e entra no terreno da ficção, da imaginação criativa, das reminiscências mitológicas, da enumeração poética etc.

Ora, o juízo não me parece de todo justo, uma vez que as obras são avaliadas por parâmetros distintos ou sob um prisma que pode não ser o mais adequado. Alguns memorialistas optam por um estilo sóbrio, mais direto e sem

11. CANDIDO. A educação pela noite \& outros ensaios, p. 53-54.

12. É mister lembrar que, em outros ensaios sobre Nabuco, Antonio Candido não poupa elogios ao grande abolicionista, lembrando como "é notável a história desse aristocrata que conseguiu sair por algum tempo do círculo de interesses da sua classe, e a quem o movimento abolicionista deu uma clarividência assombrosa, que durou cerca de dez anos." (CANDIDO. Vários escritos, p. 84). 
muitos recursos retóricos ou estilísticos, porque interessa a esses uma fidelidade, ou pretensa ilusão de fidelidade histórica aos fatos que vão sendo narrados. Outros deixam transparecer com mais evidência os sentimentos, envolvem-se mais com os fatos, liberam o imaginário e criam obras certamente mais belas ou prazerosas ao leitor. Nem por isso as primeiras são menos valiosas, enquanto informação sobre o passado, diálogo com seu tempo, ou como cada um desses memorialistas reagiu a fatos da época. ${ }^{13}$

José Aderaldo Castello atribui a três vultos de destaque em nossa cultura o surgimento do memorialismo no Brasil: José de Alencar, Joaquim Nabuco e Graça Aranha; e "memorialismo de feitura literária, elaborado com acentuada criatividade sobre a experiência individual". ${ }^{14}$ Mas essa criatividade, se se pensar na época e no propósito que norteou a escrita dessas obras, teve limites, limites que viriam a ser certamente distintos para os memorialistas do modernismo brasileiro, mineiros ou não.

Considerada a época em que foi escrita, Minha formação é já um avanço no terreno do memorialismo no Brasil, obra pioneira; se não há aí grandes vôos de imaginação, exatamente por ser um texto que pretende estar mais com o pé na História do que na ficção, como diria Pedro Nava (embora reconheçamos a fragilidade dessas fronteiras), não lhe falta valor, inclusive literário; e até mesmo o alegado narcisismo, as lacunas apontadas no texto, a ausência reclamada de dados mais íntimos, pessoais, o criticado "deslumbramento" do autor diante das nações ditas "civilizadas", sugerindo a novidade do terreno pisado, podem ser vistos como traços de uma época ainda insegura no campo do memorialismo, em que o colocarse discretamente ou não na obra, o ressaltar ou minimizar os próprios feitos, o extravasar ou não os sentimentos mais íntimos ainda constituem novidade, mesmo se consideradas a existência entre nós de obras de memórias estrangeiras, já correntes, entretanto muito distantes de nossa realidade.

13. Joaquim Nabuco, a certa altura de Minha formação, adaptado que era às leituras estrangeiras, lamenta o que ele chama de "deficiência" em relação à língua vernácula, por não possuir a sua fibra, a capacidade de "reproduzir a sonoridade da grande prosa portuguesa" (p. 77), o que é sem dúvida, de uma modéstia exagerada. Ao final do livro, observa que dali em diante o interesse político cederá lugar ao interesse religioso e literário (p. 242).

14. CASTELlO. Literatura brasileira: origens e unidade (1500-1960), vol. II, p. 385. 
José Almino Alencar, em comunicação apresentada no Instituto Histórico e Geográfico Brasileiro em 03 de dezembro de 2008, oferece julgamento positivo, vendo com olhos mais justos o valor da obra de Nabuco:

A escrita memorialística e as biografias que Nabuco escreveu são diálogos com o seu tempo e com as alternativas políticas que a sua geração enfrentava. Para ele e outros do pequeno grupo de elite que com ele dialogava, o auto-exame e os projetos biográficos estavam imbricados com o destino que imprimiriam ao futuro da sociedade brasileira e da construção da posição dessa sociedade num mundo que se modernizava. Quando falam de si ou dos outros, esses intelectuais falam quase sempre da nação "na medida em que se instituem como representantes de uma 'vontade geral' e portadores de um sentido comum a toda a sociedade". ${ }^{16}$

Os diálogos de Nabuco são bem isso: diálogos com seu tempo, não se limitando a seu país. Como bem observa no capítulo "Atração do Mundo", sua curiosidade e interesse vão "sempre para o ponto onde a ação do drama contemporâneo universal é mais complicada ou mais intensa":

Sou antes um espectador do meu século do que do meu país; a peça para mim é a civilização, e se está representando em todos os teatros da humanidade, ligados hoje pelo telégrafo. (...) A Abolição no Brasil me interessou mais do que todos os outros fatos ou séries de fatos de que fui contemporâneo; a expulsão do Imperador me abalou mais do que todas as quedas de tronos ou catástrofes nacionais que acompanhei de longe; (...) Em tudo isto, porém, há muito pouca política; (...) o que há é o drama universal de que falei, transportado para nossa terra. ${ }^{17}$

Silviano Santiago, em $O$ cosmopolitismo do pobre, no ensaio esclarecido sobre Nabuco, comentando esta passagem, observa que a incapacidade admitida pelo memorialista de viver e participar ativamente da política nacional "é

15. ALENCAR. A História em primeira pessoa, p. 8

16. CARVAlHo, in FONSECA. Casa-grande \& senzala - edição crítica, p. 878.

17. NABUCO. Minha formação, p. 54. 
o caminho enviesado e, paradoxalmente, mais correto para o cidadão brasileiro atualizado e consciente participar do projeto nacional em andamento." ${ }^{18}$

Nesse projeto, as escritas da memória, da história, do imaginário terão com certeza, sempre, seu lugar; estejam ou não cunhadas em linguagem altamente poética e sedutora. Nas palavras de Stuart Hall:

As culturas nacionais, ao produzir sentidos sobre a "nação", sentidos com os quais podemos nos identificar, constroem identidades. Esses sentidos estão contidos nas estórias que são contadas sobre a nação, memórias que conectam seu presente com seu passado e imagens que delas são construídas. ${ }^{19}$

E Joaquim Nabuco, em sua Minha formação, produziu sentidos sobre a nação com os quais seguimos nos identificando.

Joaquim Nabuco, a spectator of the century (and of himself)

Abstract: As a result of his political performance and significant participation in the abolitionist movement, the extensive work produced by Joaquim Nabuco (1849-1910) along his life provides an illuminating perspective for the understanding of the main events of the late 19th and early 20th century in Brazil, a time of deep transformations in the national scope. His writings of a memorialist nature, represented mainly by the book Minha formação, despite being acknowledged by the readers in general, have been criticized in often unfair terms, if one takes into account their historical and literary context. This paper aims to relativize some of those pieces of criticism, viewing in the memorialist the great writer, the social reformer, the observer of facts and, at the same time, the spectator of himself.

Key-words: Joaquim Nabuco; memorialism; reception.

18. santiago. O cosmopolitismo do pobre: crítica literária e crítica cultural, p. 13.

19. HALL. A identidade cultural na pós-modernidade, p. 51. 


\section{Referências}

ALENCAR, José Almino de. A história em primeira pessoa. Disponível em: <www.casaruibarbosa.gov.br>. Acesso em: 20 ago. 2010. 16p.

CANDIDO, Antonio. Poesia e ficção na autobiografia. In: A educação pela noite $e$ outros ensaios. São Paulo: Ática, 1987, p. 51-69.

CANDIDO, Antonio. Radicalismos. In: Vários escritos. São Paulo: Duas Cidades, 1995, p. $80-96$.

CARVALHO, Maria Alice Rezende de. Casa-grande \& senzala e o pensamento social brasileiro. In: FONSECA, Edson Nery da; GIUCCI, Guillermo; LARRETA, Enrique (Org.). Casa-grande \& senzala - edição crítica. Madri: UNESCO, 2002, p. 877-878. (Col. Archivos, v. 55)

CASTELlO, José Aderaldo. Produção literária do modernismo - crônica e memorialística. In: Literatura Brasileira: origens e unidade (1500-1960). V. II. São Paulo: EDUSP, 1999; 1aㅡ reimpressão 2004, p. 377-386.

FREIRE, Gilberto. Introdução. In: NABUCO, Joaquim. Minha formação. 2. ed. Brasília: Senado Federal, 2001. p. 9-23. (Coleção Biblioteca Básica Brasileira).

HALL, Stuart. A identidade cultural na pós-modernidade. 4. ed. Trad. Tomaz Tadeu da Silva, Guaracira Lopes Louro. Rio de Janeiro: DP\&A, 2000. 252 p.

LIMA, Luiz Costa. Júbilos e misérias do pequeno eu. In: Sociedade e discurso ficcional. Rio de Janeiro: Guanabara, 1986. p. 240-256.

NABUCO, Joaquim. Minha formação. Introdução de Gilberto Freire. 2. ed. Brasília: Senado Federal, 2001. 244 p. (Coleção Biblioteca Básica Brasileira)

SANTIAGO, Silviano. Atração do mundo - políticas de globalização e de identidade na moderna cultura brasileira. In: O cosmopolitismo do pobre: crítica literária e crítica cultural. Belo Horizonte: UFMG, 2004. p. 10-24. 